\title{
Policy Statement on a Dentist's Role in Treating Sleep-Related Breathing Disorders
}

Nancy Addy, DDS ${ }^{1}$; Kathleen Bennett, DDS²; Alan Blanton, DDS ${ }^{3}$; Leslie Dort, DDS ${ }^{4}$; Mitchell Levine, DMD ${ }^{5}$; Kevin Postol, DDS; ${ }^{6}$ Thomas Schell, DMD7; David Schwartz, DDS ${ }^{8}$; Rose Sheats, DMD; ; Harold Smith, DDS ${ }^{10}$; for the American Academy of Dental Sleep Medicine Board of Directors

${ }^{1}$ Snoring and Sleep Apnea Dental Treatment Center, Leawood, Kansas; ${ }^{2}$ Associated with UC Health Sleep Medicine Fellowship Program, Cincinnati, Ohio; ${ }^{3}$ Center for Dental Sleep Medicine and Orofacial Pain, University of Tennessee Health Science Center, Memphis, Tennessee; ${ }^{4}$ University of Calgary, Calgary, Alberta, Canada; ${ }^{5}$ Jacksonville Center for Snoring and Sleep Apnea, Jacksonville, Florida; ${ }^{6}$ Family and Cosmetic Dentistry, Ballwin, Missouri; ${ }^{7}$ Schellnoble Dentistry, Lebanon, New Hampshire; ${ }^{8}$ The Center for Sleep Medicine, Skokie, Illinois; ${ }^{9}$ Chapel Hill, North Carolina; ${ }^{10}$ Dental Sleep Medicine of Indiana, Indianapolis, Indiana

The American Academy of Dental Sleep Medicine (AADSM) is the only non-profit national professional society dedicated exclusively to the practice of dental sleep medicine and firmly believes that by screening and providing oral appliance therapy, dentists, with appropriate training and in collaboration with physicians, help reduce the number of undiagnosed and untreated patients with sleep-disordered breathing, which includes snoring and obstructive sleep apnea.

It is the position of the AADSM that:

- Dentists play an integral role in reducing the public health burden of undiagnosed and untreated sleeprelated breathing disorders.

- Dentists should screen patients for sleep-disordered breathing with questionnaires and by evaluating the airway.

- Physicians are responsible for diagnosing sleepdisordered breathing and primary snoring, as well as prescribing the most appropriate or acceptable treatment options.

- Education in dental sleep medicine is required in order for dentists to provide safe, quality care to patients using oral appliance therapy for sleep-related breathing disorders. At minimum, dentists should meet the educational requirements defined by the AADSM to be a "Qualified Dentist"in dental sleep medicine.

- Dentists should verify oral appliance treatment efficacy using objective data only as permitted within their scope of practice and as defined by their state dental practice acts.

- Following the fitting and initial titration of an oral appliance by a "Qualified Dentist," the patient should always be referred back to the physician. Physicians should confirm the treatment efficacy of oral appliance therapy in a timely manner.

- Dentists need to provide timely, appropriate and ongoing follow-up care to manage dental-related side effects of oral appliance therapy.

- Dentists, in close collaboration with physicians, are an integral component to successfully managing sleep-related breathing disorders with oral appliance therapy.
Sleep-related breathing disorders impact a significant portion of the population. It is estimated that 23.5 million of United States adults have undiagnosed or untreated obstructive sleep apnea-costing billions ${ }^{2}$; increasing the risk of health complications such as hypertension, congestive heart failure, atrial fibrillation, coronary artery disease, stroke and type 2 diabetes ${ }^{3}$; in addition to reducing the quality of life for a significant portion of the population.

It is imperative that dentists receive postgraduate training to be able to provide and manage oral appliance therapy and its side effects. Inappropriately chosen and monitored oral appliance therapy by an inadequately trained dentist exposes patients to potentially life-threatening outcomes and dentists to potentially serious medicolegal liability. The AADSM recommends that dentists have at minimum: a valid state dental license, proof of liability coverage, and at least 25 hours of recognized continuing education in dental sleep medicine provided by a non-profit organization focused on dental sleep medicine or accredited dental school within the last two years in order to provide oral appliance therapy to patients with sleep-disordered breathing. ${ }^{1}$ The AADSM encourages all dentists providing oral appliance therapy to become "Qualified Dentists" and subsequently Diplomates of the American Board of Dental Sleep Medicine.

Dentists play an integral role in screening patients for sleeprelated breathing disorders and referring patients to a physician for diagnosis. When oral appliance therapy is prescribed by a physician, qualified dentists provide custom-made, adjustable oral appliances, in addition to providing diligent ongoing follow-up. Dentists who are not properly trained in oral appliance therapy may provide ineffective treatment and follow-up care, potentially reducing referrals from physicians to dentists and the potential role that dentistry plays in lessening the burden of snoring and sleep apnea on public health.

\section{CITATION}

Addy N, Bennett K, Blanton A, Dort L, Levine M, Postol K, Schell T, Schwartz D, Sheats R, Smith H. Policy statement on a dentist's role in treating sleep-related breathing disorders. Journal of Dental Sleep Medicine. 2018;5(1):25-26. 


\section{REFERENCES}

1. Ramar K, Dort LC, Katz SG, et al. Clinical practice guideline for the treatment of obstructive sleep apnea and snoring with oral appliance therapy: an update for 2015. J Clin Sleep Med. 2015;11(7):773-827.

2. Frost \& Sullivan; American Academy of Sleep Medicine. Hidden health crisis costing America billions: underdiagnosing and undertreating obstructive sleep apnea draining health care system. American Academy of Sleep Medicine website. https://aasm.org/ advocacy/initiatives/economic-impact-obstructive-sleep-apnea/. Published August 8, 2016. Accessed December 11, 2017.

3. Punjabi NM. The epidemiology of adult obstructive sleep apnea. Proc Am Thorac Soc. 2008;5(2):136-143.

\section{SUBMISSION \& CORRESPONDENCE INFORMATION}

Submitted for publication December 11, 2017

Submitted in final revised form December 11, 2017

Accepted for publication December 11, 2017

Address correspondence to: American Academy of Dental Sleep

Medicine National Office, 2510 North Frontage Road, Darien, IL 60561;

Tel: (630) 737-9705; Email: info@aadsm.org

\section{DISCLOSURE STATEMENT}

Dr. Schwartz reports serving in an advisory capacity as part of Resmed's dental panel, owning public stock in Resmed, serving as part of an advisory group for Prosomnus, and having a financial stake in Prosomnus. The other authors report no conflicts of interest. 